\title{
SIMULATION OF FIRST WALL DAMAGE: EFFECTS OF THE METHOD OF GAS IMPLANTATION"
}

N. H. PACKAN and K. FAREELL

Oak Ridge National Laboratory, Oak Ridge, Tennessee 37830

Cavity formation in an austenitic alloy of similar composition to type $3 / 6$ stainless steel has been explored with regard to various methods of gas implantation. Irradiations were conducted at $900 \mathrm{~K}$ to doses of 1,10 , and $70 \mathrm{dpa}$ with helium injection ievels of 20 appm/dpa. Highest swelling (18\%) was exhibited by the unimplanted reference material; a lesser amount by simultaneous helium injection $(11 \%)$. Greatly reduced swelling due to profuse cavity nucleation was the result of the preinjection of $1400 \mathrm{appm} H e$, either at room temperature $(S=1 \%)$ or at $900 K(4 \%)$. The diclocation density was not sensitive to helium injection technique. Simultaneous injection of $50 \mathrm{appm} H / \mathrm{dpa}$, along with the He, may have caused a modesit increase in the cavity and dislocation concentrations at higher doses. The observat ions are compared with a theory of void growth iinetics to estimate the relative influence of voids and dislocations as point defect sinks.

\section{INTRODUCTION}

The first wali of a fusion reactor will be exposed to an intense high-energy neutron flux which will generate both large numbers of atonic displacements and copiwis quant ities of gascous transmutation products (helium and hydrogen). The resulting high concentrations of vacancies and interstitiols can, at certain temperotures, give rise to cavity formation. This process is promoted by the knosn facility of helium [1-4] and hydrogen [3-5] in scimulating the nucleation of bubbles. To explore such effects directly would require protracted neutron irradiations. in al ternative increasingly used is to subject specimens to charged particle bombardment which generates in only a few cours damage levels that are equivalent to vears of reactor exposure. The "transmutation broducts" must be separately

idded, elther by prior injection using an accelerator or exposure to a radioisotope source [6], or preferdbly by gas injection simultaneous vith the danage production. A reent estinaie [7] of fusion reactor gas peneration races in type 316 a!sstenitic stainess steel predicts about 12 appri hel ium/dpa Ind about 45 appm hydrogen/dpa, while those $n$ the niciel-base alloy PEI6 are about 20 and 7, respectively. In accelerator bombardments, he method of intrciluction of such quantities if gas might well be expected to jiflugnce the esult ting damage microstructure. To invest igate his, ie have made a controlled comparison of everal gas injection methods applied to a high purity $316^{\prime \prime}$ oustenitic alloy at a fixed rradiation teniperature near $900 \mathrm{~K}$ and oses ranging from 1 to 70 dpo.

Rescarch sponsored hy the Division of Aaterials Sciences, U. S. Department of Encergy under ontract w-7tos-eng-26 with the lunion Cartide. corparation.

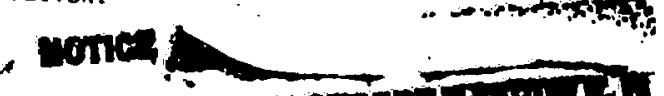

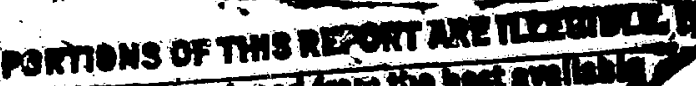

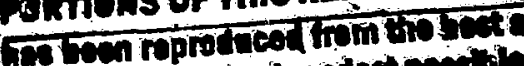

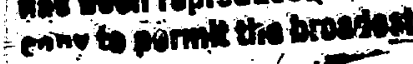

\section{EXPERIMENTAL DETAIIS}

The composition of the austenitic allcy ( $\mathrm{Fe}-17 \mathrm{wr} \% \mathrm{Cr}$, ló.7 $\mathrm{Ni}, 2.5 \mathrm{Mo}$ ) was sinilar to 316 stainiess stcei but with low $(0.005$ we $\%)$ carbon and loir residual elements (less than $0.1 \%$ each) to facilitate void formation and minimize phase instability. There was a relatively high oxygen content (1062 appm, equivalent to 0.03 wt $\%$ ). The material was cold rorked, with intermediate vacuum anneals at $1323 \mathrm{~K}$, to a final $0.5 \mathrm{~mm}$ thickness out of which $3-\mathrm{mm}$ disks were punched and then anuealed for 15 min at $1323 k$ in argon. The disks vere thei mechanically polished through 0.1 rm diamond grit and electropolished at $233 \mathrm{~K}$ to remove any vestiges of surface mechanical deformation.

Ion bombardients viere carried out using the ORNL dual accelerator irradiation facility which has recently acquired the capability $[8,9]$ of injecting boti: heliuin and deuteriun (equivalent to bydrogen) simultancousiy with the daraggecreating 4.C i:s! E:pi ion bean. Control of the irradiation parareters was siñiar to that described in previcisly cublished work [10]; in this case all bonberdments viere carried out at a temperature of $898 \pm 5 \mathrm{~K}$, which is below the peak swelling temperature of $950 \mathrm{~K}$ [1I]. The vacuum at the target was typically better zhan $10 \mu \mathrm{Pa}$. A sliding mask in front

of the taryat perinitted cach row of disks in a $3 \times 3$ array to be sombarded to difíerent doses. Nominally the attempted doses at the peok danage depths were 1, 10, and $70 \mathrm{ops}$, estimated using the ELEP-l code with an effective thrs shold encrigy of $43 \mathrm{eV}$ and a correlation factor of $0.8[12]$. The actual doses on each disk depende on the nickel beam intensity profile which was measured continunusly with an oscillating vane. Typically the nickel bear eurrent wos I particl!

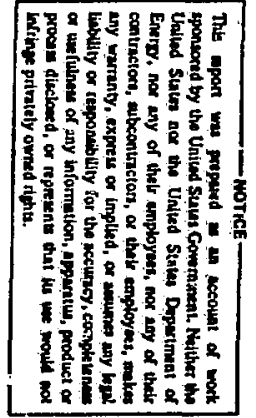

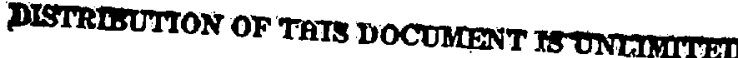




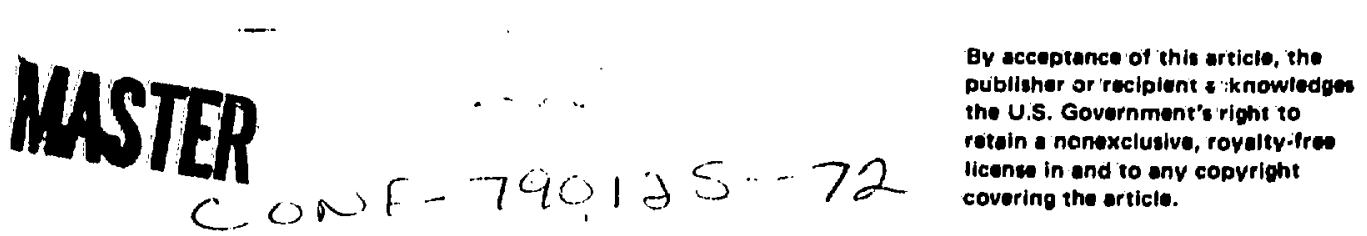

1

SIMULATION OF FIRST WALL DAMAGE: LFFECTS OF THE METHOD OF GAS IMPLANTATION*

N. H. PACKAN and K. FARRELL

Oak Ridge National Laboratory, Oak Ridge, Tennessee 37830

Cavity formation in an austenitic alloy of similar composition to type 316 stainless steel has been expiored with regard to various methods of gas implantation. Irradiations were conducted at $900 \mathrm{~K}$ to doses of 1,10 , and $70 \mathrm{dpa}$ with helium injection levels of $20 \mathrm{appm} / \mathrm{dpa}$. Highest swelling (18\%) was exhibited by the unimplanted reference material; a lesser amount by simultaneous helium injection (11\%). Greatly reduced swelling due to profuse cavity nucleation was the result of the preinjection of $1400 \mathrm{appm} \mathrm{He}$, either at room temperature $(\mathrm{s}=1 \%$ ) or at $900 \mathrm{~K}(4 \%)$. The dislocation density was not sensitive to helium injection terhnique. Simultaneous injection of $50 \mathrm{appm} H / \mathrm{dpa}$, along with the $\mathrm{He}$, may have causf:d a modest increase in the cavity and dislocation concentrations at higher doses. The obsarvations are compared with a theory of void growth kinetics to estimate the relacive influence of voids and dislocations as point defect sinks.

\section{INTRODUCTION}

The first wall of a fusion reactor will be exposed to an intense high-energy neutron flux which will generate both larse numbers of atomic displacements and copiusts quantities of gascous trarsinutation products (helium and hydrogen). The resulting high concentrations of vacancies and interstitials can, at certain temperatures, give rise to cavity formation. This process is promoied by the knom facility of hellutil [1-4] and hydrogen [3-5] in stimulating the nucleation of bubbles. To explore such effects directly would require protracted neutron irradiations. An alternative increasingly used is to subject specimens to charged particle bombardment which generates in only a few hours damage levels that are equivalent to years of reactor exposure. The "transmutation products" must be separately

added, elther by prior injecicion using an accelerator or exposure to a radioisotope source [6], or p-eferably by gas injection simultaneous $y$ ith the danage productio:. A rewent estinate [7] of fusion reactor gas generation rates in type 316 austenitic stainless steel predicts about $1.2 \mathrm{appm}$ hel ium/dpa and about 45 appm hydrogen/dpa, while those in the nickel-base alloy PEI6 are about 20 and 77, respectively. In accolcrator boinbardments, the method of introiluction of such quantities of gas might well be expected to jiflugnce the resulting damage microstructure. To investigate this, we have made a controlled comparison of several gas injection methods applied to a "high purity 316 " austenitic alloy at a fixed irradiation temperature near $900 \mathrm{~K}$ and doses ranging from 1 to $70 \mathrm{dpo}$.

Research sponsorcd by the nivision of Mucerials Sciences, U. S. Department of Entergy under contrart w-71,0s-eng-26 with the linion Carbide. Corporation.

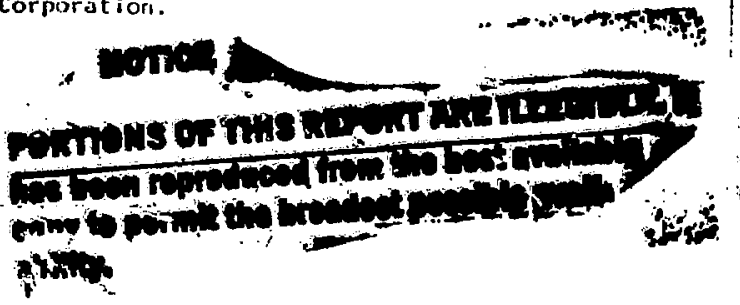

\section{EXPERISENTAL DETALIS}

The composition of the austenitic alloy (Fe-17 we $\mathrm{Cr}, 16.7 \mathrm{Ni}, 2.5 \mathrm{Ho}$ ) was sitiilai to 316 stainless steei but with lov (0.005 wt \&) carbon and low residual elements (less than $0.1 \%$ each) to facilitate void formation and minimize phase instability. There was a relatively high oxygen content (1062 appm, equivalent to $0.03 \mathrm{wt} \%)$. The material was cold worked, with intermediate vacum anneals at $1323 \mathrm{~K}$, to a final $0.5 \mathrm{~mm}$ thickness out of which $3-\mathrm{mm}$ disks were funched and then annealed for 15 min at $1323 \mathrm{~K}$ in argon. The disks vere then mechanically polished through 0.1 tim diamond grit and electropolished at $233 \mathrm{~K}$ to remove ariy vestiges of surface mechanical deformation.

Ion bombardments vere carricd out using the ORNI. dual accelerator irradiation facility which has recently acquired the capability $[8,9]$ of injecting bet helitu and deuteriun (cquivalent to hydrogen) simuitancously wi $i$ il the dainagecreating 4.C is! Eiti ion beum. Control of the irradiation pararetars was siailar to that described in previcusly published work [10]; in this: case all borbarsisents vere carried out at a temperature of $898 \pm 5 \mathrm{~K}$, which is below the peak swelling temperature of $950 \mathrm{~K}$ [11]. The vacuum at the target was typically better than $10 \mathrm{\mu Pa}$. A sliding mask in front

of the targat pernilted each row of disks in a $3 \times 3$ array to be umbarded to difierint doses. Nominally the attempted closes at the jick danage depths were 1,10 , ar:d 70 apa, est inia ced using the EDEP-1 cocle with an elfective threstoid encrgy of $4 \mathrm{~J} \mathrm{eV}$ and a correiation fa:tor of 0.8 [12]. The actual doses on each disk dependt on the nickel bein intensity prorile wich was measured continuously witi on corillating vane. Typically the nickel bearn surrent was 1 particl!

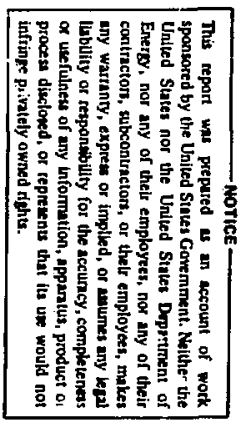

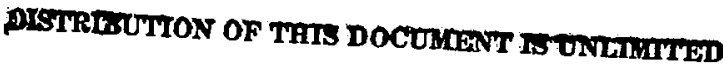


in, yialtirig a disnlacenell rate of about $6.1 \times 10^{-3} \mathrm{dpa}_{\mathrm{p}} \cdot \mathrm{s} i$ in peak damols rogion. The currents in the gas line were set by $t r i a l$ and error at about $110 \mu \mathrm{A}$ of $\mathrm{He}^{+}$and $140 \mu \mathrm{A}$ of $\mathrm{D}_{2}^{+}$ so as to give 20 at. $\mathrm{ppm} \mathrm{He} / \mathrm{dpa}$ and 50 at. ppm $0 /$ dpa at the peak damage depth.

Following ion bombardment specimens $: \because e=2$ lac: rochemically thinned from the bombarda? sills to a depth of $0.6 \mathrm{kim}$, and then fruii tha bagr: side to perforution. They were then examined in a JEM 100-C electron, microscope which could reveal cavities as small as $2 \mathrm{~nm}$ diam. Foil thicknesses were determined by stereo microscop\%. Errors frotn these mensurchents, tosecher vith soctionimg errors in obtaining a ioil near the pisk danaye depth and problems with spatially-

inhusojemeous dafect distributions, contrilute

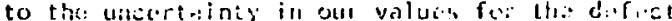

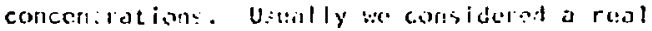
difference in defiet concentir. ions to be greater than a factor of 2 to 3 . Swelling values were computed directly from the cavity sizes and concentrations per ASTM recommendations [12].

The alternitive niethods of gas injection which. were explored in this experilitent bere: situl. tuncous injection of heliun; preinjection of helium at room temperature (RT); proinjection at tho subsecuent darage procluction teriperoture : of $900 \mathrm{~K}$; and simultaneous injection of hydrogen (actually deuterium) along with helium. The preinjected specimens were either given a fixed 1400 appm He implantation regardless

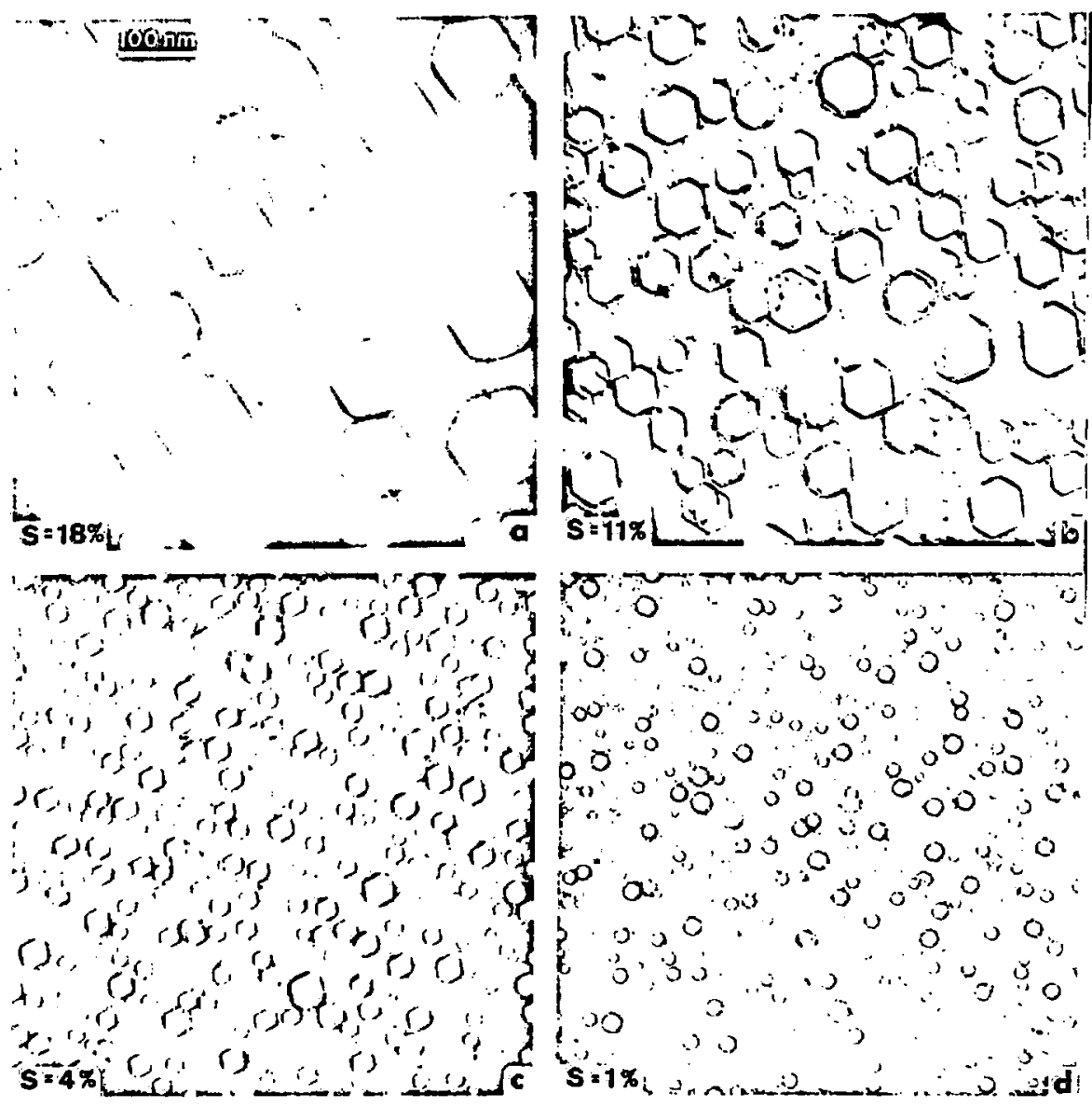

Fig. 1. Examples of void sizes and concentrations produced by a bombardment at $900 \mathrm{~K}$ to $70 \mathrm{dpa}$. (a) No added gas; (b) simultaneous injection of a cumulative $1400 \mathrm{at}$. ppm He; (c) preinjection of $1400 \mathrm{ppm}$ He at $900 \mathrm{~K}$; and (d) preinjection of $1400 \mathrm{ppm}$ He at room temperature. 
of their subsequerit displacement-producing exposure, or were preimplanted at RT with 20 appm and $200 \mathrm{appm} \mathrm{He}$ and subsequently bombarded to $\mathrm{I}$ and $10 \mathrm{dpa}$, respectively. Specimens bombarded without any added gas were used as the reference conoition.

\section{RESULTS}

Different methods of introducing helium can indeed profoundly affect the final damage r:orphology as is evidont in Fig. 1. In cach case (except la, no gas) the same amount of hel $i$ un (1400 at. Ppm) :as introduced into a spacitnen that ultinately received about 70 dpa at $900 \mathrm{k}$. The largest swelling, 18\%, was seen for the material with no added gas, Fig. la. Less swelling was exhibited by the specimens given simultaneous gas injection: the dual beam situation (Fig. Ib) ylelded $11 \%$ while a triple ion bombardment (not shown) resulted in $13 \%$ swelling. The two preinjection techniques caused substantially lower swelling, apparently as a result of intensified cavity nucleation and restrained cavity growth. In Fig. IC, preinjection at $900 \mathrm{~K}$ followed directly by niskel ion bombardment at the same temperature yielded a swolling of $4 \%$, while preinjection at room temperature produced the most abundant nicleation and a swelling of only $1 \%$.

The development of swelling at lower doses is shown in Fig. 2, wherein it appears that all but one of the various irradia-

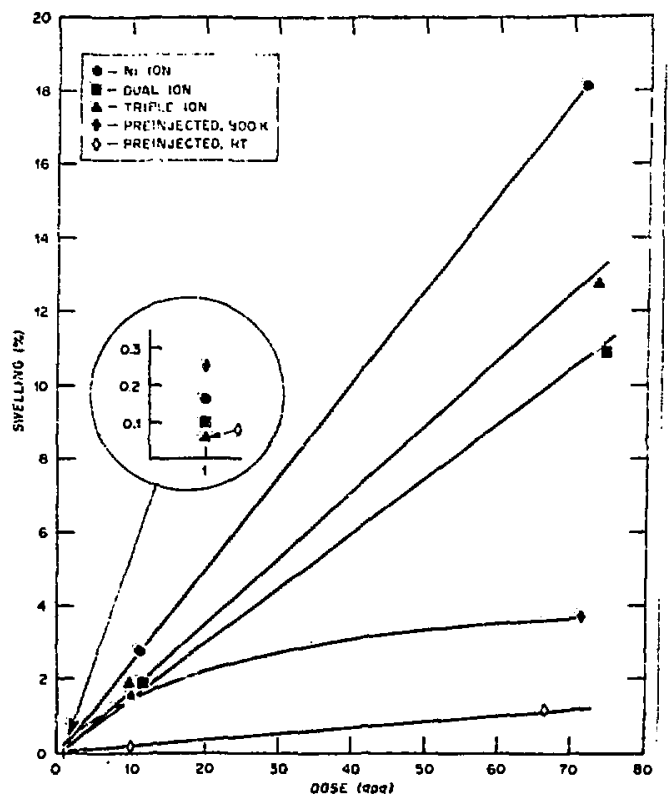

Fig. 2. Dependence of swelling upon dose for the gas injection methods studled. tion techniefues rellict a limar stalling with dose, each with ils oun wisigue solling rate.

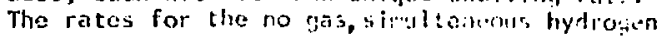
plus heliun, simultanesus, l:slitw, and RT foreinjection cases ares 0.26, 0.13,0.15, end 0.016 s per dpa. The elevated tempartule preinjection data afpear to shate the slope of the si,nit.meons injections at low doses, but later drop down to approximately the swelling rate of RT preinjection. The RT preinjection experiment in which $\mathrm{He} / \mathrm{dpa}=20$ was held constant, rather than a fixed $1400 \mathrm{ppm}$ He, showed a very low swelling of $0.003 \%$ at 1 dpa and $2.9 \%$ at $11 \mathrm{dpa}$. Clearly the different methods of gas introducion create a disparity in swelling that increases with dose.

Figures 3-5 show data on the microstructural characteristics (mean cavity diameters, concentrations, and dislocation densities) resulting from the various bombardment methods. The reference condition evidently attained its high swelling by means of a high cavity growth rate and in spite of declining cavity numbers. Simultaneous injection of helium caused swelling roughly similar to that for the helium plus hydrogen case, but there is an interesting contrast in their cavity generation rates. The dual beam samples show roughly constant cavity numbers, whereas those of triple beam bombardment exhibit a steadily-rising cavity concentration through $70 \mathrm{dpa}$ (from quite a low value at $1 \mathrm{dpa}$ ).

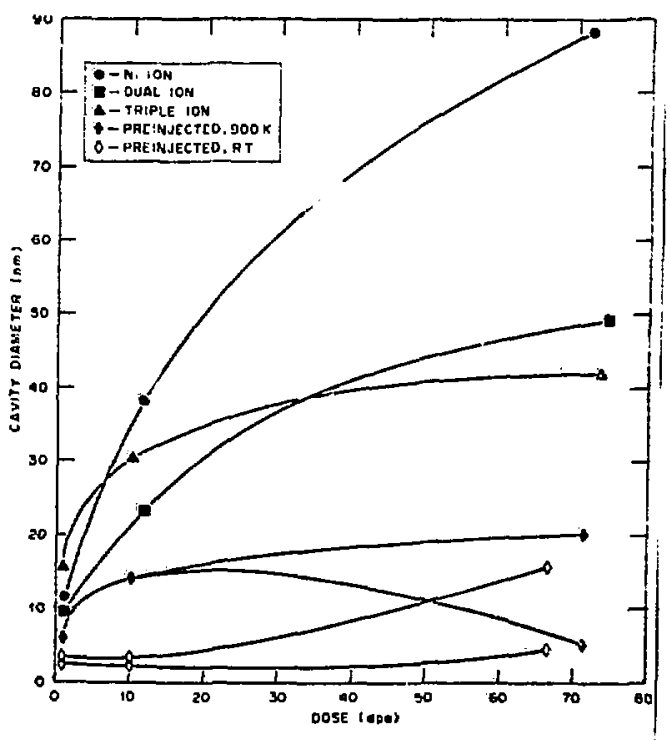

Fig. 3. Diameter of a cavity of mean volume as . a function of dose. Certain preinjection conditions gave rise to bimodal size distributions, indicated here by pairs of data points. 


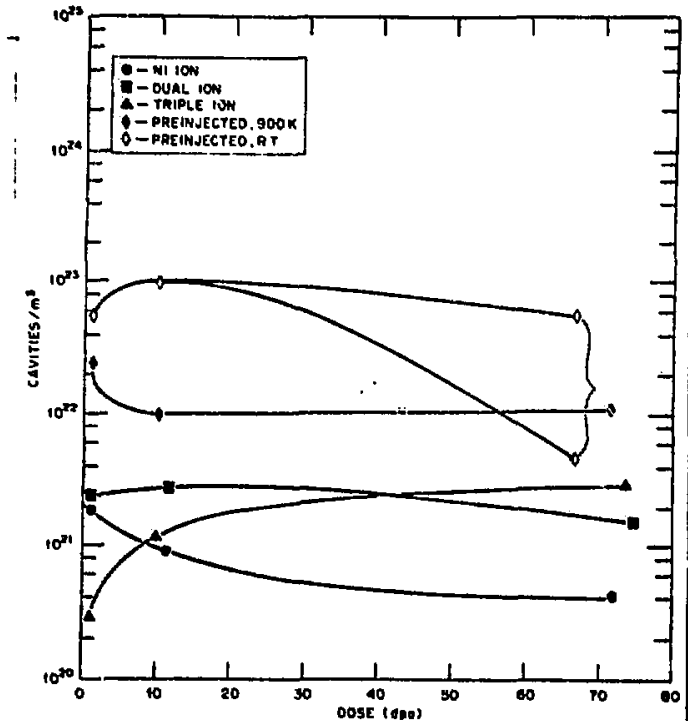

F1g.4. Disparate behavior of the cavity concentration with dose for vartous methpds of gas introduction.

$\therefore$ Preinjection of 1400 ppm He brought about drastic swelling reduction through profuse initial nucleation of cavities which evidently competed with one another, allowing little cavity growth. The RT preinjection, in fact, gave rise to a sharply bimodal cavity size distribution. The smaller group (4 nm mean diam) grew negligibly over the dose range studies, perhaps because they were just below a critical size for void growth. Preinjection at $900 \mathrm{~K}$ ultimately generated a bimodal size idistribution quantitatively simiiar to that of RT

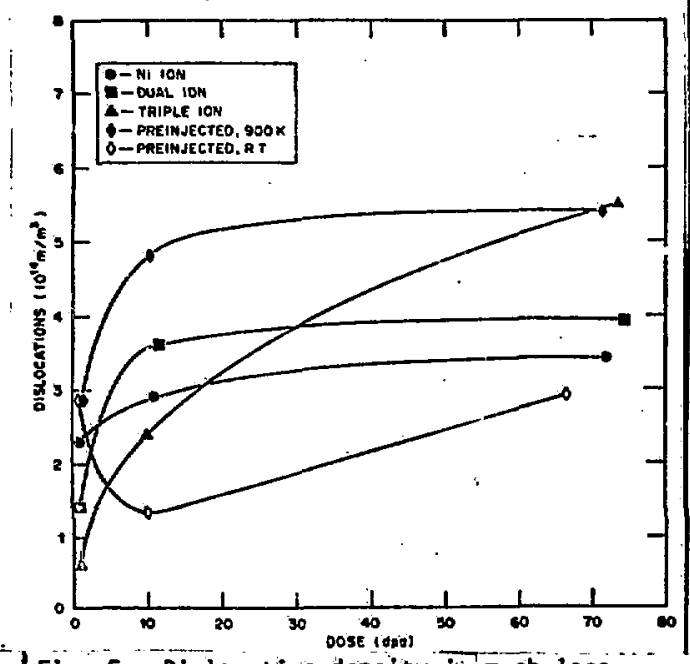

Fig. 5. Dislocation density is much less sensitive to gas implantation technique than is the void density. preinjection also at $70 \mathrm{dpa}$, but up to $10 \mathrm{dpa}$ the cavities of high-temperature preinjection were more like those of simultaneous injection (or the no-gas case).

The dislocation ciensity (Fig. 5) was not iespecially sensitive to the method of gas injection, having variations of no more than a ? factor of 3 . It may or may not be significarit (abuve scatter) that while most specimens exhibited a plateau in dislocation density after: inlo dpa, the material injected with helium plus hydrogen showed a persistent increase over the iwhole dose range, analogous to the increase it also showed in cavity density. The RTpreinjected material once more behaved in a contrary fashion.

\section{DISCUSSION}

The refurence specimens bombarded with only nickel ions swelled significantly more than thos: subjected to any of the gas implantation tecciniques, a high swelling that resulted from the highest void growth rate. such behavior can be expected from an inherently high-swelling material which fosters immediate void nucleation on preexisting sites and on a scale not so fine as to hinder subsequent void growth. Voids in this material were frequently observed in strings or other heterogeneous spatial distributions, most likely resulting from nucleation on similarly-distributed gases or other indigenous impurities. Simultaneous (dual and triple ion) gas injection resulted in ireduced but still substantial swelling and lower. cavity growth rates. The dual-ion irradiation also yielded cavity and dislocation concentrations comparable to the nickel-ion i.radiation.

These basically similar results despite the gradual addition of 1400 appm He. indicate that again cavity nucleation must have been essentially set at the beginning, and that hel ium was added too slowly (even at our 20 appm $\mathrm{He} / \mathrm{d}$ ä ratel to make a major change. Such a result would not be expected for a material in which cavity nucleation is difficult, and in fact Kenik [13] has observed a profound influence of simultaneously-injected He in the low swelling alloy LSIA. A similar variation in the effectiveness of simultaneously implanted helium depending on the relative ease of cavity nucleatlon withou't helium has been noted before by Brimhail and simonen $[14,15]$.

In the case of the triple-ion bombardments, both the initial (1 dpa) dislocation and cavity concentrations were notabiy low, yet both values increased continuously with dpa through the highest dose studied. This suggests that the simultaneous addition of hydrogen might play a modest but continuing role in sustaining cavity nucleation in this type of material. However, caution is advisable because such a trend was not found in our bombardinents conducted at. or above the peak swelling temperature [11].

$\rightarrow$ The preinjection of 1400 appin He had a marked effect on the damage microstructures. PreinJection at room temperature produced $10^{23}$ cavi- 
lies/a and a swelling of only $1:$ at $70 \mathrm{dpa}$. The spatial distribution of these ntwiterous. cavities was quite uniform which implies that here the injected helium has assumed the dominant

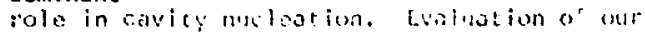

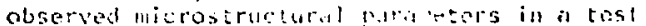

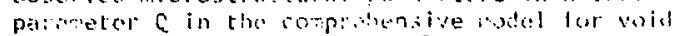
growth kinetics by Mansur [16] indicates that

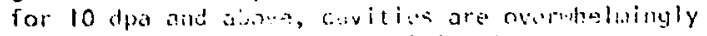
the doninant sinh for GT i.reinjectiori, wheres; veids and dislecetions are abut equally inportant for the simblennes:s injertion ond nothel ium cases. The stediling vis duse behavior of $900 \mathrm{k}-$

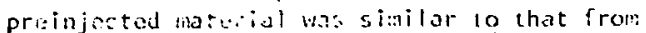
dual-ion hombardeent up to $10 \mathrm{dpo}$ (hhough the covity concentratior was throe tilles higher and the cavities only half as big). However, from 10 to $70 \mathrm{dpa}$ this microstructure increasingly came to resemble that of $R T$ preinjection. The initial dissimilarity from RT preinjection is presumbly due to the fact that at the beginning of bombardment there were many more nuclei present that were greater than the critical size for growth; hence mean covity dialleter and swelling initially increased rutch more rapidty. Evidrently tho initial nucleation wos nevertheless profuse enough to linit the cavitios rrom groving as larg: as those fron sialultans us injection.

That hot preiniecion can give lareper fant presumably faver) nuclui than loes RT preinjec$t$ ion was shown by Mazey and Nelson [17] who investigated as-implanted 316 stainiess steel and observed defect clusters anu helium bubbles for implantations made at $773 \mathrm{~K}$ and above. Comparing then specimens implanted with 100 appm He at RT and $873 \mathrm{~K}$ followed by bombardment with $46.5 \mathrm{MeV}$ $\mathrm{Ni}$ ions to $40 \mathrm{dpa}$, they observed the same trends reported here: larger and fewer cavities and greater swelling for clevated temperature (ET) preinjection versus RT preinjcction. A more recent comparison by McGruer et al. [18] of ET and RTpreinjection and simultancous helium i jjection '(80 appm/dpa) of 304 stainless steel is only partially consistent with these findings. Their results for RT preinjecticin and dual-ion bombardment (all to $5.15 \mathrm{dpa}$ ) are quantitatively similar to the 10 dpa values of this experiment. However, the hot preinjection $(925,975$, and $1025 \mathrm{~K}$ ) trials yielded cavitius tnree times larger and seven times fewer than those of simultancous bombardment, a relationship opposite to our result. Possibly the higher temperatures of their study may be partially responsible for the difference. One impcrtant point of agreement between the currert investigation and all of the prior works [15,1], 18] is that the total dislocation content is very little affected by the mathod of heliun int roduction.

\section{SUMMARY}

Different modes of gas introduction strongly affect cavity formation in this free-swelling material. The disparitias generally increase with dose as far as $70 \mathrm{dpa}$. The unimplantcd reference material swells the most due to a high voicl groulh raiu. Silwltanous injection of helium (20 appm/dpa) yields a lower swelling and a nearly-censtant concentration of cavities over tha dose range studied. Prinjection of the same to:nl amount of helium at room temperature gives profuse cavity nucleation and the lowest swellini. Preinjection of helium at the subsequent havy ion bombardmerit temperature $(900 \mathrm{~K})$ results in low-dose swelling similar to simultaneous helium injection, changing over to resemble RT preinjection by $70 \mathrm{dpa}$. The total dislocation density is not significantly alfected by the method of helium introduction. Simultanecus injection of 50 appm/dpa hydrogen ma: have a tendency to prolong cavity and dislocation nucleation for itradiations below the peak swelling temperature.

\section{REFEREIICES}

[1] R. S. Nelson and D. J. Mizey, hathati..:

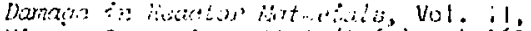
Vienna syrricasiun, iAE (196́) 154-i6j.

[2] E. E. Blowin and J. O. Sticgler, 7 . int. liftes. $36(19 \% 0) 331$.

[3] K. Farrell, A. Volfenden, and R. T. king,

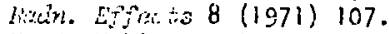

[4] M. J. Makin, J. A. Hudson, D. J. Mazer, R. S. Nelson, G. P. Walters, and T. M. Willians, Radintion Demast in resetis Hatericiz, Proceetings of Confercnce, Scottsdale, Arizona, 1977 (itst. Soc. of AlME (1977) U4 5-665.

[5] J. T. Buswell, S. B. Fisher, J. E. Harbotil,

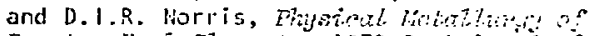
Rocitor Wez Stements, 1073 Barkelesi Conf. (Metais Society, London, 1975) 170-174.

[6] N. H. Packan arid W. A. Cognhlan, k: $c^{*}$ ? Tect:?0\%. 40 (1978) 208.

[7] T. A. Cabriel, B. L. Bishop, and F. W. Wirfen, fmol. Tectill. 38 (1973) 208.

[8] K. Farroll, A. B. Lowis, and H. H. Packon, Seniptex lest. 12 (1978) 1121.

[9] H. B. Levis, Promedings of conjonsto:

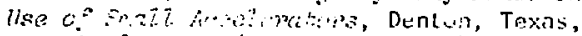
Nov. 1978, lete (to be pulilished).

[10] N. H. Packan, K. Firreil, and J. O. Stioslar.

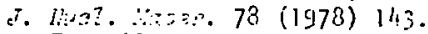

[11] K. Farrell and K. H. Pac! an, this confulence.

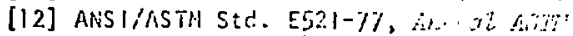

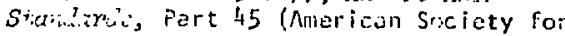
Testing and Heterials (19\%) 98:.

[13] E. A. Kenik, this conference.

[14] J. L. Brimhel] and E. P. Simuils, Rarr?. Techinoz. $29(1976) 378$.

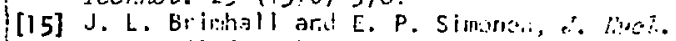
inter. 68 (15/7) 235.

[16] L. K. Mansur, M. Men?., 10 (1978) 5.

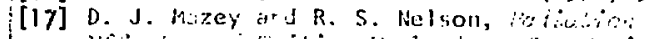

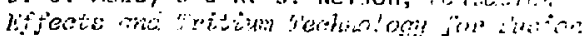
Feroior., USEREA CDHF 750383 , Vol. 1 (197\%) 240-25S.

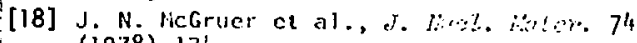
(1978) $17 l_{4}$. 